\title{
NAKED LOBOSE AMOEBAE OF THE GENUS MAYORELLA (AMOEBOZOA, DISCOSEA, DERMAMOEBIDA) IN UKRAINIAN WATER BODIES
}

\author{
M. K. Patsyuk \\ Zhytomyr Ivan Franko State University, Vel. Berdychivska st., 40, Zhytomyr, 10008 Ukraine \\ E-mail: kostivna@ukr.net
}

Naked Lobose Amoebae of the Genus Mayorella (Amoebozoa, Discosea, Dermamoebida) in Ukrainian Water Bodies. Patsyuk, M. K. - In Ukrainian water bodies, the genus Mayorella Schaeffer, 1926 is represented by ten species: Mayorella cantabrigiensis Page, 1983, Mayorella vespertilioides Page, 1983, Mayorella bigemma Schaeffer, 1918, Mayorella leidyi Bovee, 1970, Mayorella penardi Page, 1972, Mayorella viridis Leidy, 1874, Mayorella sp. (1), Mayorella sp. (2), Mayorella sp. (3), Mayorella sp. (4). The most widely distributed are M. cantabrigiensis, M. vespertilioides, Mayorella sp. (1), the least observed are M. leidyi, M. penardi, M. viridis, Mayorella sp. (4). The distribution of amoebae is influenced by abiotic environmental factors.

Key words: naked amoebae, Mayorella, Ukrainian water bodies, abiotic factors.

\section{Introduction}

Schaeffer erected the genus Mayorella in 1926 with the type species Mayorella bigemma (Amoeba bigemma) Schaeffer, 1918 (Glotova et al., 2018). In the current system of naked lobose amoebae (Smirnov et al., 2011), this genus belongs to the class Discosea Cavalier-Smith et al., 2004, order Dermamoebida Cavalier-Smith, 2004, family Mayorellidae Schaeffer, 1926. The amoebae have mayorellian morphotype (Smirnov \& Goodkov, 1999), generally with undivided fingerlike hyaline subpseudopodia of approximately equal length produced out of hyaline cytoplasm; in some species, subpseudopodia may be temporarily absent during locomotion. The length of moving mayorellian amoebic body exceeds its width. The floating amoeba has acute pseudopodia spreading out of irregularly shaped central cell mass, vesicular nucleus, and one big nucleolus (Goodkov \& Buryakov, 1987). Mayorella-like amoebae are widely distributed in soils and fresh and sea waters. Based on light microscopy and electron microscopy of the cellular surface, eight species are recognized: fresh-water Mayorella cantabrigiensis Page, 1983, Mayorella vespertilioides Page, 1983, Mayorella penardi Page, 1972, Mayorella viridis Leidy, 1874, and seawater Mayorella kuwaitensis Page, 1983, Mayorella gemmifera Schaeffer, 1926, Mayorella dactylifera Goodkov and Buryakov, 1988, and Mayorella pussardi Hollande, Nicolas \& Escaig, 1981 (Glotova et al., 2018). 


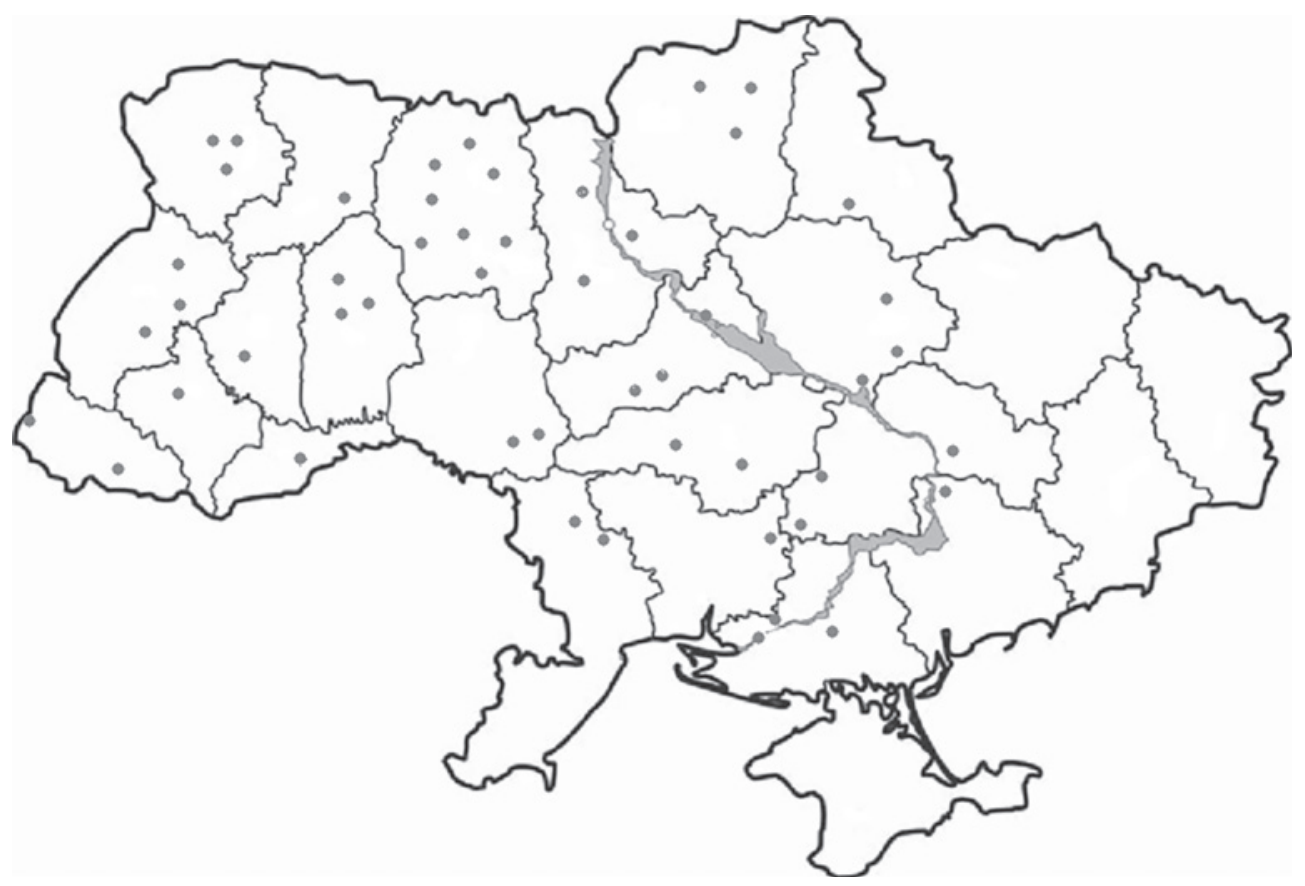

Fig. 1. Sampling localities (Ukraine).

There are reports, based on light and electron microscopy and molecular biology methods, according to which the genus Mayorella is richer than the described eight species (Glotova et al., 2018). There is almost no data on naked amoebae fauna of the habitats with differing environmental conditions and of remote locations. That is why it is necessary to sample in distant habitats and compare findings with local faunas (Smirnov et al., 2011). Since naked amoebae remain poorly studied in Ukraine, we investigated the Mayorella species isolated from Ukrainian water bodies.

\section{Material and methods}

Material was collected in 2011-2018 in various water bodies of Ukraine (fig. 1), resulting in 360 samples from 48 locations. We employed modern light microscopy methods, including DIC, to study c. 120 Mayorellalike amoebae. It should be noted that a full range of approaches and methods (including ultrastructural and molecular biological) are currently used for exact identification of naked amoebae. Therefore, our taxonomic identification does not pretend to unambiguity. The morphological data are used for the identification of naked amoebae in many faunistic studies. .

The samples of water and disturbed bottom sediment were manually collected into glassware of up to $500 \mathrm{ml}$ and transferred to the laboratory. Amoebae were isolated from samples containing the upper layer of bottom soil and a small quantity of bottom water. They were cultured on Petri dishes of $50 \mathrm{~mm}$ diameter on non-nutrient agar (Page \& Siemensma, 1991) at $15^{\circ} \mathrm{C}$. We used the light microscope Zeiss AxioImager M1 at the Centre for collective usage of scientific equipment "Animalia" of I. I. Schmalhausen Institute of Zoology with differential contrast optics for observations of living cells in water droplets on the slides.

We recorded the temperature, dissolved oxygen and organic matter concentration (by permanganate oxidation) of the studied water bodies during sampling (Stroganov \& Buzinova, 1980).

We used the Chekanovsky-Sørensen index to compare the faunistic lists. The clustering was bootstrapped and the multi-dimensional scaling was done in PAST 1.18 (Hammer et al., 2001).

\section{Results and discussion}

In this study we identified 10 amoeba species of the genus Mayorella: M. cantabrigiensis, M. vespertilioides, M. bigemma, Mayorella leidyi Bovee, 1970, M. penardi, M. viridis, Mayorella sp. (1), Mayorella sp. (2), Mayorella sp. (3), Mayorella sp. (4). (fig. 2, table 1) (Patsyuk, 2012, 2013, 2014, 2016 a, b, 2018; Patcyuk \& Dovgal, 2012).

We established the occurrence frequency of amoeba, since the absolute quantities could not be calculated for this group. The most common species were M. cantabrigiensis 
Table 1. Characters of amoebae of the genus Mayorella from Ukrainian water bodies

\begin{tabular}{c|l|c|c|c|c|}
\hline No & Amoebae species & Cell length, $\mu$ & Cell breadth, $\mu$ & Length to breadth ratio, $\mathrm{L} / \mathrm{B}$ & Nucleus diameter, $\mu$ \\
\hline 1. & M. cantabrigiensis & $90-110$ & $45-60$ & $2.5-3.6$ & $3.0-3.6$ \\
2. M. vespertilioides & $85-100$ & $50-75$ & $1.3-1.8$ & $10.0-15.0$ \\
3. M. bigemma & $110-285$ & $100-85$ & $2.5-3.5$ & $11.0-11.8$ \\
4. M. leidyi & $105-185$ & $60-100$ & $2.8-3.0$ & $11.0-11.5$ \\
5. M. penardi & $43-50$ & $18-24$ & $3.2-4.0$ & $4.0-6.0$ \\
6. M. viridis & $45-55$ & $26-28$ & 1.6 & $5.0-9.0$ \\
7. Mayorella sp. (1) & $100-130$ & $50-70$ & $2.1-3.7$ & $8.0-12.0$ \\
8. Mayorella sp. (2) & $50-95$ & $25-40$ & $2.0-2.5$ & 6.5 \\
9. Mayorella sp. (3) & $62-120$ & $30-84$ & $1.8-3.2$ & $5.8-11.0$ \\
10. Mayorella sp. (4) & $40-60$ & $15-20$ & 4.8 & $6.2-6.8$ \\
\hline
\end{tabular}

(60.20\%), M. vespertilioides (50.32\%), Mayorella sp. (1) (50.03\%), the rarest were Mayorella sp. (4) (0.25\%), M. leidyi (0.9\%), M. penardi (0.5\%), M. viridis (1.3\%). The frequency of $M$. bigemma in Ukrainian water bodies was $30.25 \%$, Mayorella sp. (2) $31.01 \%$, and Mayorella sp. (3) $28.32 \%$. We analyzed the effect of temperature, levels of oxygen and organic matter (by permanganate oxidation) on most common Mayorella species: $M$. cantabrigiensis was an eurythermal organism, found at +2 to $+26^{\circ} \mathrm{C} ; M$. vespertilioides and Mayorella sp. (1) were collected mostly in warm season at +16 to $+26^{\circ} \mathrm{C}$. Mayorella sp. (1) tolerated high oxygen concentrations (4.35 to $31.94 \mathrm{mg} / \mathrm{l}$ ) and was euryoxidic; $M$. cantabrigiensis and $M$. vespertilioides were recorded at oxygen levels under $17.84 \mathrm{mg} / \mathrm{l}$ meaning that they were stenooxidic. M. cantabrigiensis was found at the highest organic matter concentration $\left(50.05 \mathrm{mg} \mathrm{O}_{2} / \mathrm{l}\right)$, probably the most favorable to its development. M. vespertilioides (24.45 $\left.\mathrm{mg} \mathrm{O}_{2} / \mathrm{l}\right)$ and Mayorella sp. (1) (28.53 $\left.\mathrm{mg} \mathrm{O}_{2} / \mathrm{l}\right)$ were sensitive to dissolved organic matter levels.

The distribution of the Mayorella species in various types of Ukrainian water bodies was analyzed according to a hydrobiological classification of continental waters (Konstantinov, 1986). Most amoebae were found in rivers (eight species) and riparian basins (seven), only two were discovered in channels, and three were collected in swamps. Four species of amoebae were found in lakes (table 2).

Only Mayorella sp. (1) was recorded in all types of water bodies and can be considered eurytopic. Three species were found only in lakes or rivers: $M$. penardi and $M$. viridis were observed only in lakes, and Mayorella sp. (2) was collected in rivers because of hydrochemical and trophic specifics of the waters. The other six species were found in water bodies of

Table 2. Distribution of naked amoebae of the genus Mayorella in various water bodies of Ukraine

\begin{tabular}{|c|c|c|c|c|c|c|}
\hline \multirow{2}{*}{ No } & \multirow{2}{*}{ Amoeba species } & \multicolumn{5}{|c|}{ Water basin type } \\
\hline & & river & swamp & channel & riparian basin & lake \\
\hline 1. & M. cantabrigiensis & + & + & - & + & - \\
\hline 2. & M. vespertilioides & + & - & - & + & + \\
\hline 3. & M. bigemma & + & - & - & + & - \\
\hline 4. & M. leidyi & + & - & - & + & - \\
\hline 5. & M. penardi & - & - & - & - & + \\
\hline 6. & M. viridis & - & - & - & - & + \\
\hline 7. & Mayorella sp. (1) & + & + & + & + & + \\
\hline 8. & Mayorella sp. (2) & + & - & - & - & - \\
\hline 9. & Mayorella sp. (3) & + & + & + & + & - \\
\hline 10 & Mayorella sp. (4) & + & - & - & + & - \\
\hline Tota & & 8 & 3 & 2 & 7 & 4 \\
\hline
\end{tabular}




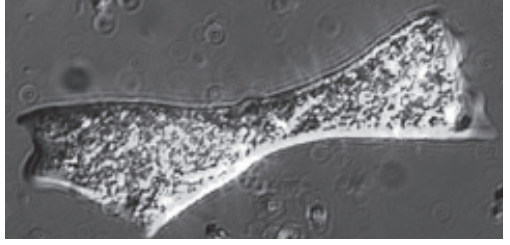

$a$

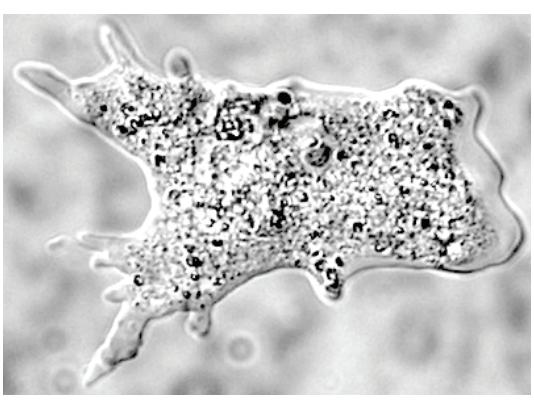

$c$

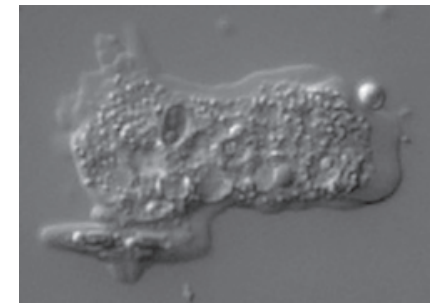

f
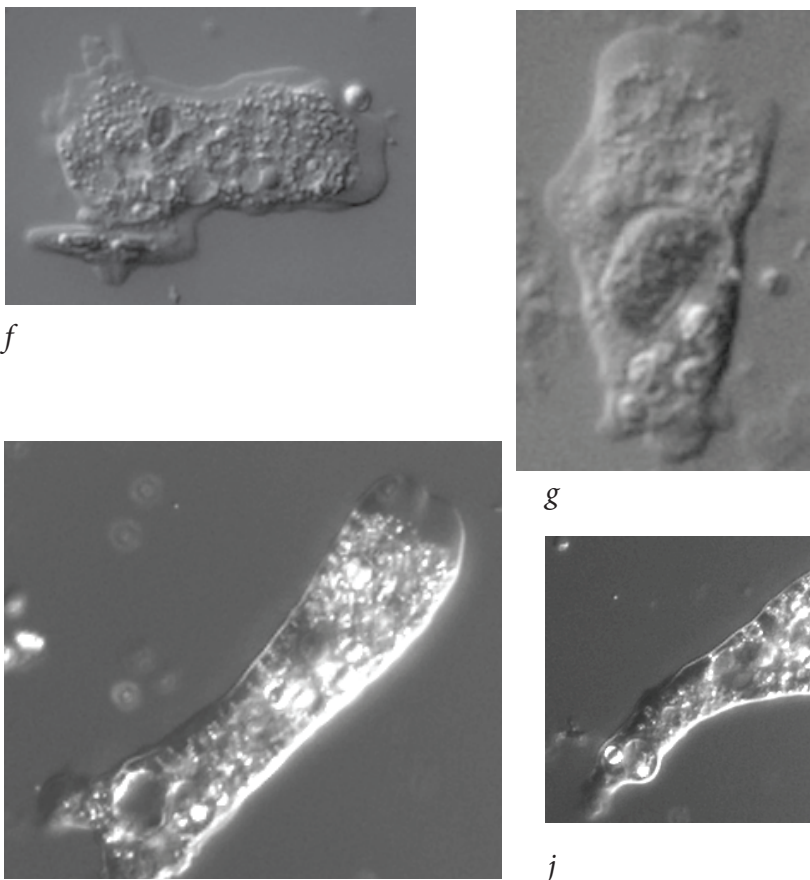

g
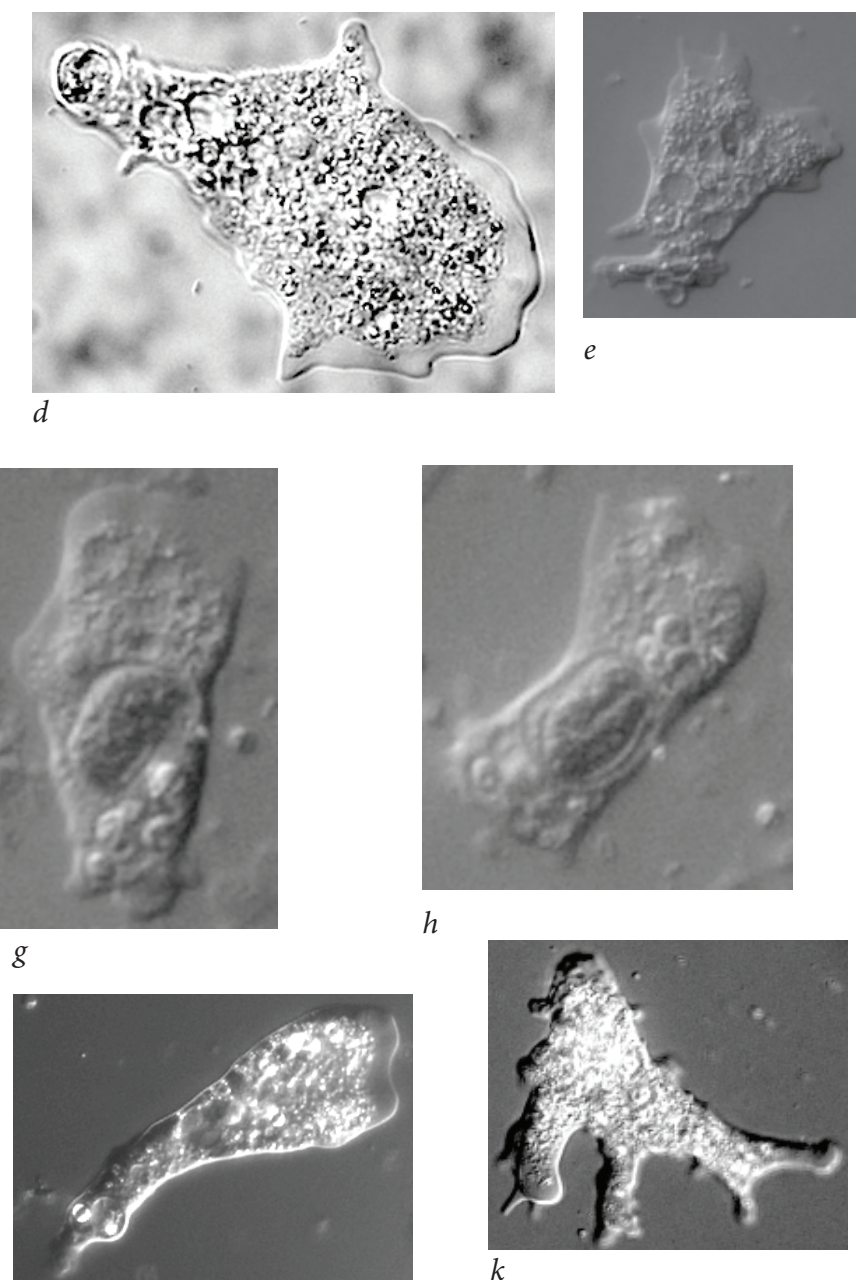

$e$

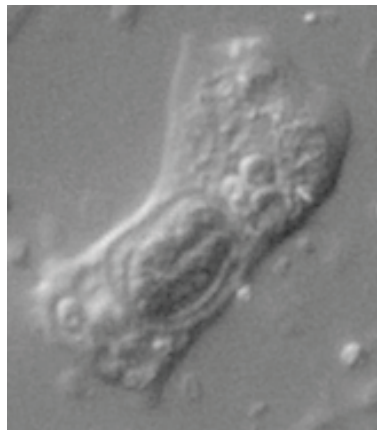

h

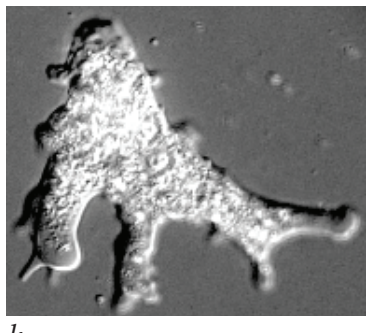

j

$i$

Fig. 2. Naked amoeba of the genus Mayorella found in different water bodies of Ukraine: $a, b-$ M. cantabrigiensis $\times 1240$; $c, d-M$. vespertilioides $\times 1240$; e, $f-M$. penardi $\times 1240$; $g$, $h-M$. viridis $\times 1240$;

i, $j$ - Mayorella sp. (1) $\times 1240$;

$k, l-$ Mayorella sp. $(2) \times 1240$; m, $n-$ Mayorella sp. (4) $\times 1240$.

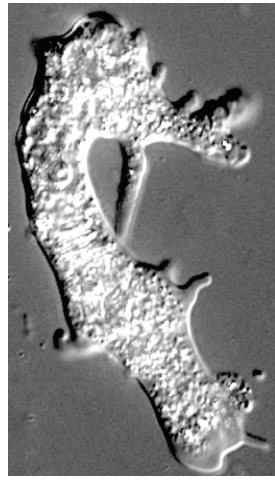

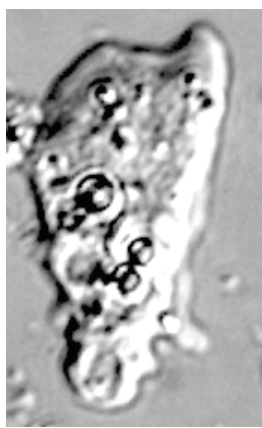

m

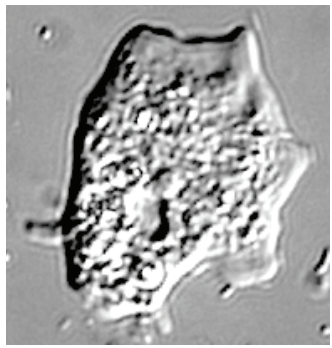

$n$ 
two or more types, possibly indicating tolerance to wide environmental ranges (table 2).

According to the Chekanovsky-Sørensen index, the most similar assemblages of Mayorellalike amoebae were those of rivers and riparian basins (0.93), and the least common assemblages were from swamps and lakes (0.28). Only 0.36 of species were common for lakes and other types of water bodies. According to the cluster analysis (fig. 3), amoebae species lists formed a lake species complex (Shatsky Lakes) and a cluster of riparian basins, rivers, swamps, and channels species complex. The probability of existence of the two clusters was bootstrapped (1000 permutations) and equaled $100 \%$ and $64 \%$, respectively.

The first cluster of amoebae

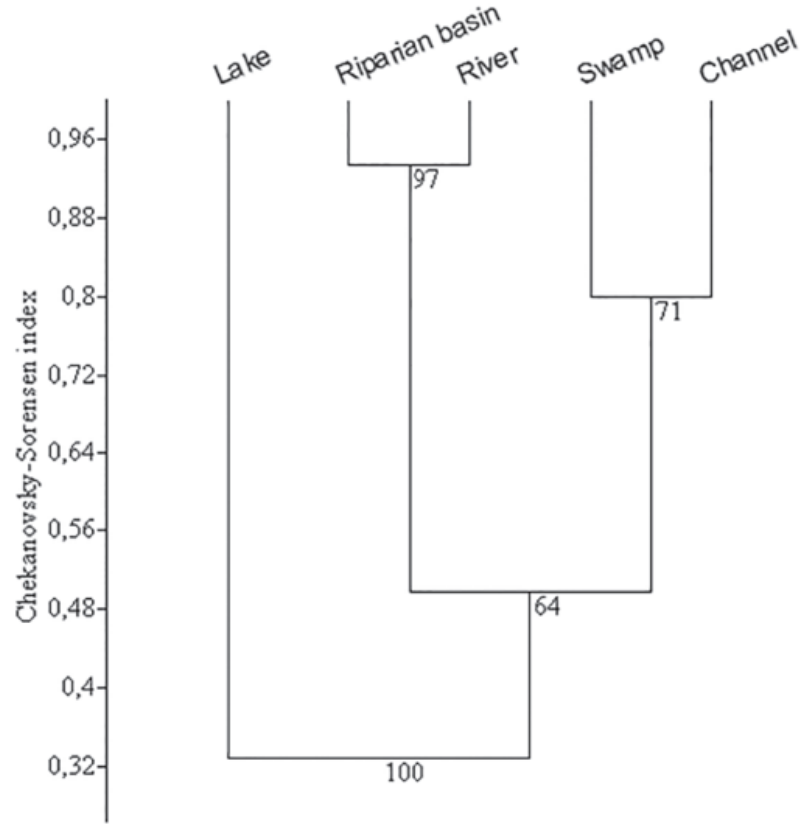

Fig. 3. Similarity of Mayorella amoebae complexes in various types of water bodies in Ukraine according to the ChekanovskySørensen's index (numbers in the nodes show the \% probabilities of clusters at 1000 bootstrap permutations).

arose from specific conditions in lakes (mostly sand-silt bottom, calcium-hydrocarbonate water with low minerals levels); and the second cluster ("riparian species complex") formed in basins connected to rivers and thus they are interlinked.

Besides that, Mayorella species complexes in Ukrainian waters were influenced by temperature as well as dissolved oxygen and organic matter concentrations. Figure 4 shows that the riparian species complex of Mayorella-like amoebae is formed at relatively higher temperatures and higher concentrations of organic matter compared to that of the lakes. The lake complex was defined by low temperature and low organic matter levels. Oxygen levels had a weak effect on the lake and riparian species complexes. This factor will be studied in more detail in our further work.

Therefore, there are 10 amoeba species of the genus Mayorella in lakes of Ukraine. In relation to abiotic factors, M. cantabrigiensis is eurythermal; Mayorella sp. (1) is euryoxidic; $M$. cantabrigiensis and $M$. vespertilioides are stenooxidic; $M$. cantabrigiensis tolerates high organic matter content, and M. vespertilioides and Mayorella sp. (1) do not have tolerance to such conditions. Species

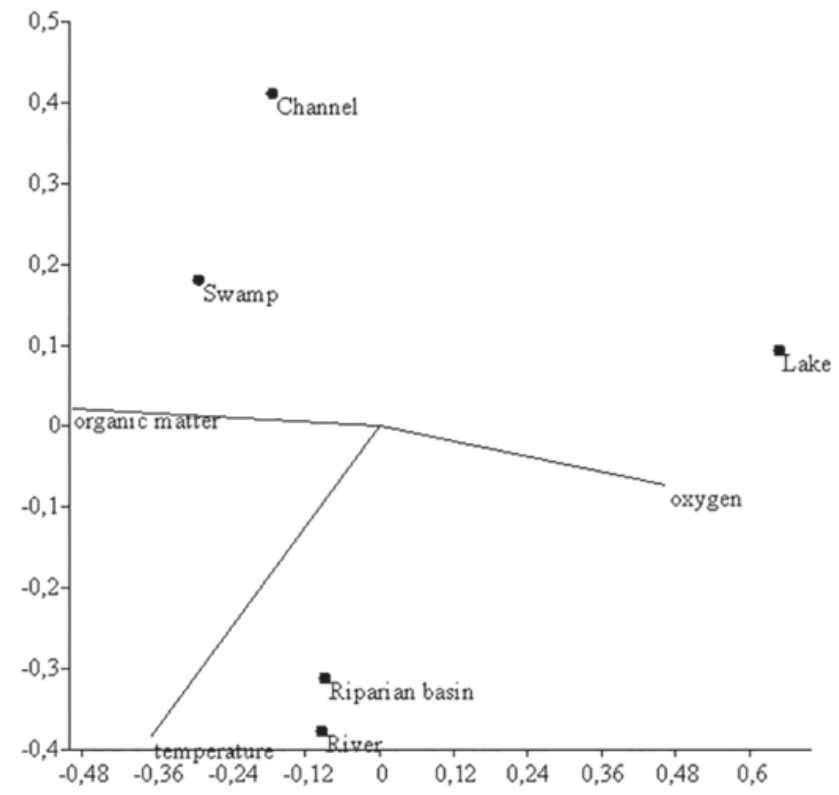

Fig. 4. Ordination of Mayorella-like amoebae species complexes in various types of water bodies by environmental factors (according to non-parametric multi-dimensional scaling). 
of Mayorella form a lake species complex and a riparian complex, both tied to certain abiotic factors.

Notably, M. cantabrigiensis was isolated from a remote fresh-water basin in Germany, meaning that this protist can be widely distributed. The Ukrainian fauna of mayorellians is probably not confined to ten species. Small number of species we have so far found can be an artifact of sample transportation, culturing, and species identification. Further research is necessary to determine the distribution of these protists using methods of light and electron microscopy and molecular biology.

\section{References}

Glotova, A., Bondarenko, N., Smirnov, A., 2018. High Genetic Diversity of Amoebae Belonging to the Genus Mayorella (Amoebozoa, Discosea, Dermamoebida) in Natural Habitats. Acta Protozool., 5, 29-42.

Goodkov, A. V., Buryakov, V. Yu., 1987. Mayorella dactylifera sp. n. (Gymnamoebia, Paramoebidae) and an overview of marine Mayorella species. Zool. jorn., 67 (6), 927-931.

Hammer, Ø., Harper, D. A. T., Ryan, P. D., 2001. PAST: Palaeontological statistics software package for education and data analysis. Palaeontol. electronica, 4 (1), 1-9.

Konstantinov, A. S., 1986. General hydrobiology: a textbook for universities. Vysshaya shkola, Moscow, 406-414 [In Russian].

Page, F. C., Siemensma, F. J. 1991. Nackte Rhizopoda und Heliozoea (Protozoenfauna Band 2). Gustav Fischer Verlag, Stuttgart, NewYork, 3-170.

Patsyuk, M. K., 2012. New Gymnamoebae species (Gymnamoebia) in the fauna of Ukraine. Vestnik Zoologii, 46 (2), 105-111.

Patsyuk, M. K., Dovgal, I. V., 2012. Biotopic distribution of naked amoebes (Protista) in Ukrainian Polissya area. Vestnik Zoologii, 46 (4), 355-360.

Patsyuk, M. K., 2013. Tolerance of Naked Amoebas (Protista) to the Abiotic Factors. Nature Montenegrina, 12 (2), 319-323.

Patsyuk, M. K., 2014. Morphotypes in Naked Amoebas (Protista): Distribution in Water Bodies of Zhytomyr and Volyn Polissia (Ukraine) and Possible Ecological Significance. Vestnik Zoology, 48 (6), 547-552.

Patsyuk, M. K., 2016 a. Seasonal changes in the species composition of naked amoebas (Amoebina) of the Teterev river (the Town of Zhitomir). Hydrobiological Jornal, 52 (4), 55-62.

Patsyuk, M. K., 2016 b. Naked Amoebae of Ukrainian Polissya Fauna. Protistology, 10 (2), 58.

Patsyuk, M. K., 2018. Peculiarities of the Spatial Distribution of Naked Amoebas in Sandy Bottom Sediments of a Small River. Hydrobiological Jornal, 54 (5), 102-111.

Smirnov, A., Goodkov, A. 1999. An illustrated list of basic morphotypes of Gymnamoebae (Rhizopoda, Lobosea). Protistology, 1, 20-29.

Smirnov, A., Chao, E., Nassonova, E., Cavalier-Smith, T., 2011. A Revised Classification of Naked Lobose Amoebae (Amoebozoa: Lobosa). Protist, 162, 545-570.

Stroganov, N. S., Buzinova, N. S., 1980. A practical guide to hydrochemistry. Moscow, 1-196 [In Russian].

Received 16 April 2019

Accepted 25 October 2019 